\title{
Bone pain and extremely low bone mineral density due to severe vitamin $D$ deficiency in celiac disease
}

\author{
Noortje M. Rabelink • Hans M. Westgeest • \\ Nathalie Bravenboer • Maarten A. J. M. Jacobs • \\ Paul Lips
}

Received: 18 April 2011 / Accepted: 20 April 2011 /Published online: 15 June 2011

(C) The Author(s) 2011. This article is published with open access at Springerlink.com

\begin{abstract}
Case report A 29-year-old wheelchair-bound woman was presented to us by the gastroenterologist with suspected osteomalacia. She had lived in the Netherlands all her life and was born of Moroccan parents. Her medical history revealed iron deficiency, growth retardation, and celiac disease, for which she was put on a gluten-free diet. She had progressive bone pain since 2 years, difficulty with walking, and about $15 \mathrm{~kg}$ weight loss. She had a short stature, scoliosis, and pronounced kyphosis of the spine and poor condition of her teeth. Laboratory results showed hypocalcemia, an immeasurable serum 25-hydroxyvitamin D level, and elevated parathyroid hormone and alkaline phosphatase levels. Spinal radiographs showed unsharp, low contrast vertebrae. Bone mineral density measurement at the lumbar spine and hip showed a T-score of -6.0 and -6.5 , respectively. A bone
\end{abstract}

N. M. Rabelink $(\bowtie) \cdot$ H. M. Westgeest $\cdot$ P. Lips

Endocrine Section, Department of Internal Medicine,

VU University Medical Center Amsterdam,

Postbox 7057, 1007 MB Amsterdam, The Netherlands

e-mail: n.rabelink@vumc.nl

H. M. Westgeest

e-mail: HM.Westgeest@vumc.nl

P. Lips

e-mail: p.lips@vumc.nl

N. Bravenboer

Endocrine Research Laboratory,

VU University Medical Center Amsterdam,

Amsterdam, The Netherlands

e-mail: n.bravenboer@vumc.nl

M. A. J. M. Jacobs

Department of Gastroenterology,

VU University Medical Center Amsterdam,

Amsterdam, The Netherlands

e-mail: MAJM.Jacobs@vumc.nl scintigraphy showed multiple hotspots in ribs, sternum, mandible, and long bones. A duodenal biopsy revealed villous atrophy (Marsh $3 \mathrm{C}$ ) and positive antibodies against endomysium, transglutaminase, and gliadin, compatible with active celiac disease. A bone biopsy showed severe osteomalacia but normal bone volume. She was treated with calcium intravenously and later orally. Furthermore, she was treated with high oral doses of vitamin $\mathrm{D}$ and a gluten-free diet. After a few weeks of treatment, her bone pain decreased, and her muscle strength improved.

Discussion In this article, the pathophysiology and occurrence of osteomalacia as a complication of celiac disease are discussed. Low bone mineral density can point to osteomalacia as well as osteoporosis.

Keywords Celiac disease - Osteomalacia - Vitamin D - Bone mineral density $\cdot$ Histomorphometry

\section{Introduction}

Low bone mineral density is the first diagnostic criterion in patients with osteoporosis. Osteomalacia is however also characterized by a low BMD. In this article, we will present a patient referred to our hospital with an extremely low bone mineral density due to severe osteomalacia with longstanding celiac disease. It is important to distinguish between osteoporosis and osteomalacia because they differ with regard to therapy and prognosis.

\section{Case history}

A 29-year-old woman of Moroccan origin was admitted to the Department of Gastroenterology because of refractory 
celiac disease and suspected osteomalacia. Her medical history revealed growth retardation and iron deficiency from the age of 6 and the diagnosis of celiac disease at the age of 17. At the age of 27 , there was an ongoing symptomatic celiac disease despite a gluten-free diet. On admittance to our hospital, the patient complained of progressive bone pain over the last 2 years, mainly located in the ribs, spine, hips, and shoulders. She also had severe difficulty with walking and was in fact wheelchair-bound. She was short of breath during normal daily activities and had lost $15 \mathrm{~kg}$ in 3 years. She had a regular menstrual cycle, and her menarche was at 17 years of age. She had neither abdominal complaints nor diarrhea. On physical examination, she was pale. Her body height was $148 \mathrm{~cm}$ (previously $156 \mathrm{~cm}$ ) and her weight, $38 \mathrm{~kg}$. She had bad dentition, and the back showed a scoliosis and pronounced thoracic kyphosis with thoracic and lumbar percussion pain. Pelvis and shoulders also were painful on touching. There was muscle atrophy and symmetrical loss of proximal muscle strength.

Laboratory evaluation at presentation showed hypocalcemia, low serum phosphate, high alkaline phosphatase, and a serum 25-hydroxyvitamin D $(25(\mathrm{OH}) \mathrm{D})$ level below the detection limit, as shown in Table 1. The serum parathyroid hormone level was strongly elevated. Furthermore, the patient had low serum vitamin A $(0.9 \mu \mathrm{mol} / \mathrm{L}$; normal, 1.2-3.0), vitamin B1 (78 nmol/L; normal, 80-160), and vitamin B6 (6 nmol/L; normal, 13-80) levels. Her serum folic acid level (30.7 nmol/L; normal, $>6)$ and serum vitamin B12 level were normal (150 pmol/L; normal, 10-700), and there were no signs of iron deficiency. At that moment, she was using the following medications prescribed in the referring hospital: calcium carbonate $1,000 \mathrm{mg}$ twice daily, naproxen $500 \mathrm{mg}$ twice daily, pantoprazole $20 \mathrm{mg}$ once daily, tramadol $50 \mathrm{mg}$ twice daily, ferrioxidesaccharaat $200 \mathrm{mg}$ once a week (intravenous), alfacalcidol $0.5 \mu \mathrm{g}$ once daily (intravenous), alendronic acid $70 \mathrm{mg}$ once a week, and folic acid $5 \mathrm{mg}$ once daily (intravenous).

Radiographs of the thoracic and lumbar spines had a milk glass appearance and were not sharply delineated. The lumbar vertebrae had a biconcave codfish appearance (Fig. 1a, b) Bone mineral density measurement (Hologic) showed extremely low absolute values and T-scores (Table 1). A skeletal scintigraphy with technetium-99 M showed a diffusely elevated uptake in sternum, mandible, and long bones and an absent kidney sign. There were also multiple symmetric focal lesions with enhanced uptake in the ribs, compatible with rib fractures or fissures (Fig. 2a, b). To confirm the clinical diagnosis of osteomalacia in this patient with severe refractory celiac disease and extremely low BMD, a bone biopsy was obtained from the right iliac crest (Fig. 3a-c). This biopsy showed a relative osteoid volume of more than $70 \%$ and signs of increased bone turnover compatible with secondary hyperparathyroidism. The osteoid was covered with high
Table 1 Results of laboratory evaluation, BMD measurement and histomorphometry

\begin{tabular}{lll}
\hline Laboratory evaluation & Patient & Reference values \\
Calcium & $1.94 \mathrm{mmol} / \mathrm{L}$ & $2.20-2.60 \mathrm{mmol} / \mathrm{L}$ \\
Phosphate & $0.71 \mathrm{mmol} / \mathrm{L}$ & $0.70-1.40 \mathrm{mmol} / \mathrm{L}$ \\
Albumin & $35 \mathrm{~g} / \mathrm{L}$ & $35-52 \mathrm{~g} / \mathrm{L}$ \\
Alkaline phosphatase & $386 \mathrm{U} / \mathrm{L}$ & $<120 \mathrm{U} / \mathrm{L}$ \\
25 hydroxy vitamin D & $<10 \mathrm{nmol} / \mathrm{L}$ & $25-150 \mathrm{nmol} / \mathrm{L}$ \\
1,25 hydroxy vitamin $\mathrm{D}^{\mathrm{a}}$ & $76 \mathrm{pmol} / \mathrm{L}$ & $50-160 \mathrm{pmol} / \mathrm{L}$ \\
Parathyroid hormone (fasting) & $75 \mathrm{pmol} / \mathrm{L}$ & $<11 \mathrm{pmol} / \mathrm{L}$ \\
& & \\
DXA & $\mathrm{BMD}$ & $\mathrm{T}-\mathrm{score}, \mathrm{Z}-\mathrm{score}$ \\
LWK (L1-L4) & $0.390 \mathrm{~g} / \mathrm{cm}^{2}$ & $-6.0,-6.0$ \\
Hip & $0.153 \mathrm{~g} / \mathrm{cm}^{2}$ & $-6.5,-6.4$ \\
& & \\
Bone histomorphometry & & \\
Trabecular bone volume $(\%)$ & $\mathrm{BV} / \mathrm{TV}=37.48 \%$ & \\
Osteoid (\%) & $\mathrm{OV} / \mathrm{BV}=75.07 \%$ & \\
Trabecular thickness & $261 \mu \mathrm{m}$ & \\
Osteoid thickness & $98.5 \mu \mathrm{m}$ & \\
\hline
\end{tabular}

${ }^{\text {a } A f t e r ~ i n i t i a t i n g ~ v i t a m i n ~ D ~ t h e r a p y ~}$

numbers of active osteoblasts, and resorption lacunae were filled with multinucleated osteoclasts. Peri-trabecular fibrosis was also observed. The trabecular bone volume (BV/TV) was normal, i.e., not compatible with osteoporosis.

This Moroccan young woman with refractory celiac disease had a very severe osteomalacia with an extremely low bone mineral density due to a severe vitamin D deficiency. Treatment with alendronic acid was discontinued, and the patient was treated during 14 days with intravenous calcium glubionate up to $8,250 \mathrm{mg}$ ( $540 \mathrm{mg}$ or $13.5 \mathrm{mmol}$ $\mathrm{Ca}^{++}$) daily and oral cholecalciferol 10,000 IU daily. After these 14 days, her medication consisted of $7 \mathrm{~g}$ of calcium carbonate and 1,200 IU cholecalciferol daily in an outpatient setting. After the intravenous treatment, the serum $25(\mathrm{OH}) \mathrm{D}$ level increased to $56 \mathrm{nmol} / \mathrm{L}$, and the symptoms of the patient rapidly improved; the bone pain decreased, muscle strength and physical performance improved markedly, and she was able to walk unassisted.

After initiating oral treatment with calcium and lowering the cholecalciferol dose, there was a gradual decline of $25(\mathrm{OH}) \mathrm{D}$, and we had to increase the oral dose of cholecalciferol to 10,000 IU a day. Questioning revealed gluten exposure and patient was given advice repeatedly on how to maintain a strict gluten-free diet. After raising the oral dose of cholecalciferol, the serum 25(OH)D level increased to $34 \mathrm{nmol} / \mathrm{L}$, and the 1,25 $(\mathrm{OH})$ vitamin $\mathrm{D}$ to $>250 \mathrm{pmol} / \mathrm{L}$. Bone mineral density measurement $51 / 2$ months after initiation of therapy showed a significant increase at the lumbar spine (L1-L4) and hip, 


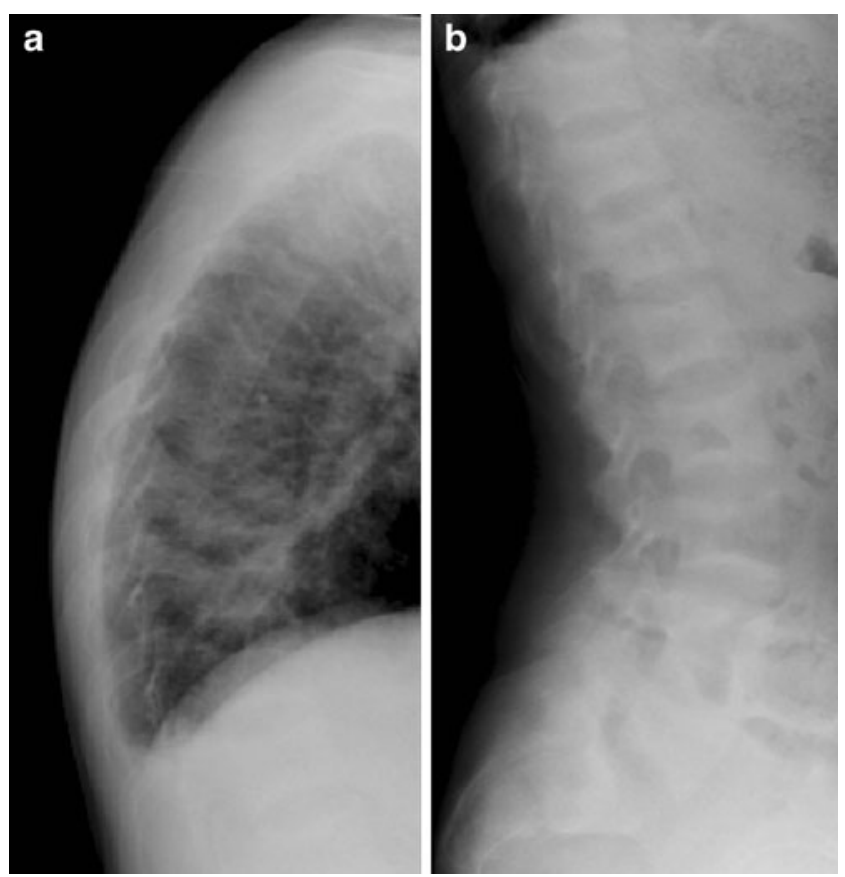

Fig. 1 Radiographs, lateral view, of the lower thoracic (a) and lumbar vertebrae (b). Thoracic vertebrae are blurred and lumbar vertebrae show codfish appearance

$0.44 \mathrm{~g} / \mathrm{cm}^{2}$ (T-score, -5.5$)$ and $0.22 \mathrm{~g} / \mathrm{cm}^{2}$ (T-score, -5.9 ), respectively. Further follow-up of this patient was not possible because she did not respond to multiple invitations to visit our outpatient clinic.
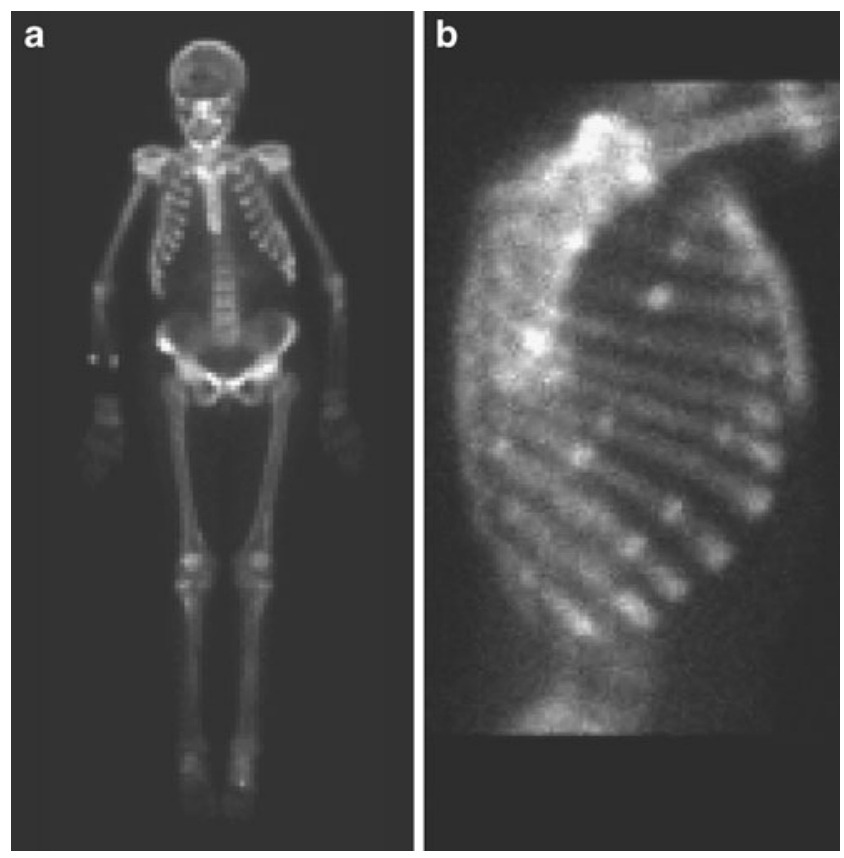

Fig. 2 Bone scintigraphy; Whole body, anterior view (a) and detail of the ribs, lateral view (b). Hot spots may indicate pseudofractures or fissures
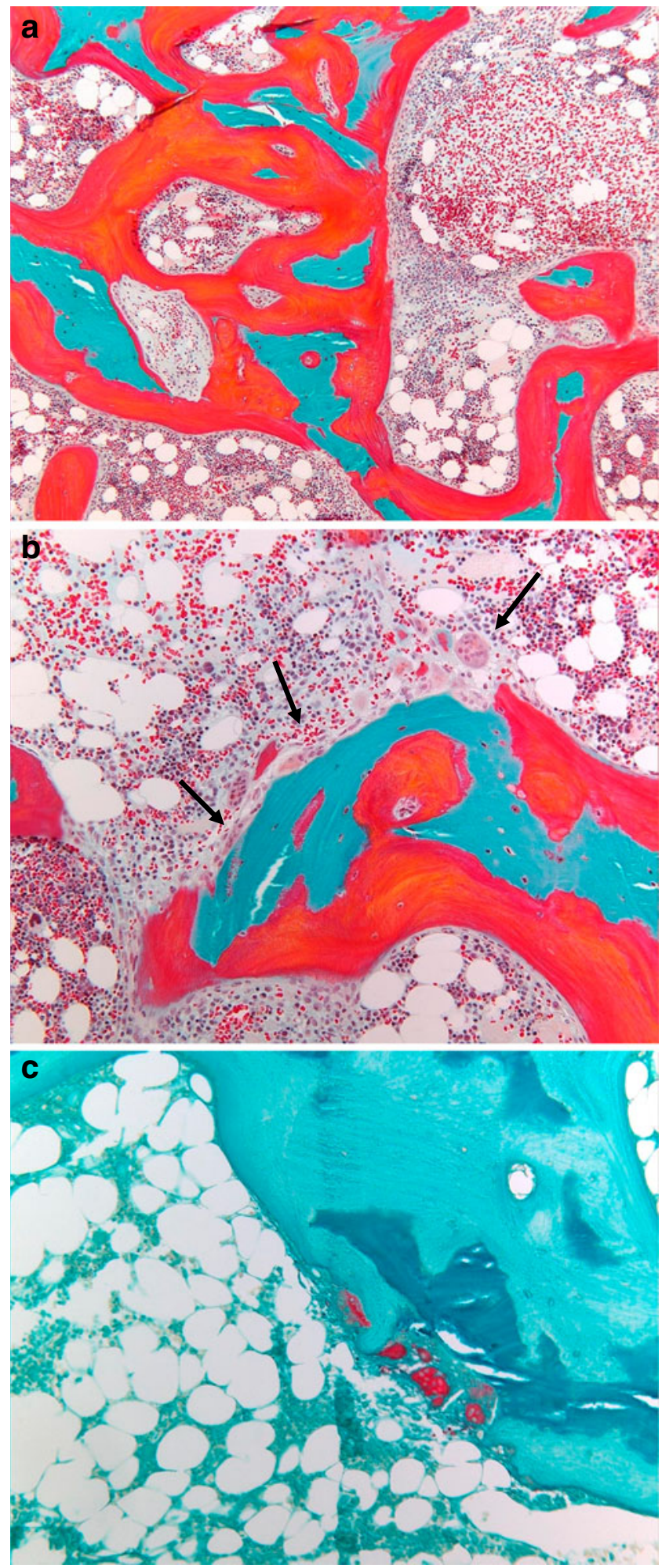

Fig. 3 Crista biopsy; Goldner stain, magnification $5 \times 10$ (a), Goldner stain, magnification $10 \times 10$ (b), and Tartrate-resistant acidic phosphatase stain, magnification $10 \times 10$ (c). Mineralized bone is green and osteoid tissue, red. Osteoid seems very thick, and osteoid volume is $75 \%$. Bone resorption by multinucleated osteoclasts is increased (arrows) 


\section{Discussion}

Osteomalacia is seldom described as a complication of celiac disease and rarely seen as presenting clinical condition $[2,5,10]$. In our patient, osteomalacia was a late complication of ongoing celiac disease due to poor compliance regarding gluten-free diet. Osteomalacia may occur as a consequence of severe longstanding vitamin D deficiency when sunshine exposure is very low [10, 24]. Sunshine exposure still is the main source of vitamin D. It is highly likely that in our patient, a pigmented skin, covered by clothes, and the northern latitude of the Netherlands have contributed to the severity of the osteomalacia. Also, calcium malabsorption causes secondary hyperparathyroidism, and the latter results in an enhanced metabolic breakdown of vitamin D metabolites [3, 4, 14, 19, 22]. Calcium malabsorption in celiac disease is due to villous atrophy in the proximal intestine. Villous atrophy causes a reduction of active absorption of calcium and an increase of unbound intraluminal fatty acids that bind intraluminal calcium and inhibit absorption. Vitamin $\mathrm{D}$ receptor resistance in the intestinal wall has been suggested, and the amount of vitamin D-dependent calcium-binding proteins in the intestinal wall appears to be reduced in active disease [19]. Other factors could also reduce bone mineral density, such as secondary amenorrhea induced by low body weight [6, 13, 18], lactose intolerance, immobility [9], inflammation [7, 20], and antibodies against regulating proteins [17].

Common symptoms of osteomalacia are proximal muscle weakness, difficulty with walking and especially climbing stairs, a waddling gait, difficulty with rising out of a chair, and bone pain [9]. After initiating treatment for osteomalacia, the symptoms typically disappear within weeks to months $[8,10]$. During clinical recovery, the alkaline phosphatase rises temporarily due to enhanced bone formation, after which it normalizes. The relatively high serum level of 1,25-dihydroxyvitamin D as compared to $25(\mathrm{OH}) \mathrm{D}$ is due to secondary hyperparathyroidism that causes an enhanced $1 \alpha$-hydroxylase activity [11].

Response to therapy is illustrated very elegantly in an early case report by Gershon et al. Symptoms, biochemical markers of bone turnover, and bone structure normalized within several months after initiating vitamin D therapy, and an electromyography of different muscles improved markedly [9].

This patient illustrates all features of severe osteomalacia: a low serum calcium and phosphate, an elevated alkaline phosphatase, a very low bone mineral density, signs of bone fissures or pseudofractures on skeletal scintigraphy, and unsharp milky radiographs with codfish vertebrae. The bone biopsy showed severe osteomalacia and secondary hyperparathyroidism. The very low serum $25(\mathrm{OH}) \mathrm{D}$ and the severe consequences may also be due to the fact that she was a non-western immigrant. The latter group carries a high risk of severe vitamin D deficiency in the Netherlands as serum 25(OH)D was lower than $25 \mathrm{nmol} / \mathrm{L}(10 \mathrm{ng} / \mathrm{ml})$ in about half of Turkish and Moroccan immigrants in a recent survey [23]. The unsharp delineation of the radiographs is probably due to the very thick osteoid seams, about seven times the upper limit of normal. The height loss of the patient may be due to vertebral height loss. It might partly be reversible since this is also seen in patients with juvenile osteoporosis.

Our patient had severe mobility problems and muscle weakness. In order to initiate a quick improvement, she was treated with calcium infusions since oral calcium would not be absorbed adequately before healing of the glutensensitive enteropathy. Bone mineralization does not depend on vitamin D as long as sufficient calcium and phosphate are available [25]. The therapeutic use of calcium infusions has been described earlier [1].

Several studies examined bone mineral density in adults with celiac disease consuming a gluten-free diet. Most studies show a decrease in BMD which improves when a gluten-free diet is instituted, but loss of BMD is usually not fully reversible $[4,12,15,16,21]$. Most patients will experience bone loss due to secondary hyperparathyroidism following vitamin $\mathrm{D}$ deficiency. Another aspect is that that a very low BMD can indicate osteomalacia as well as osteoporosis.

In celiac disease, osteomalacia should be suspected when the patient complains of bone pain and muscle weakness, serum $25(\mathrm{OH}) \mathrm{D}$ is very low, and alkaline phosphatase is elevated. It is seldom the presentation of an undiagnosed celiac disease. Therapy should be initiated as soon as possible to prevent bone loss and disability.

Conflicts of interest None.

Open Access This article is distributed under the terms of the Creative Commons Attribution Noncommercial License which permits any noncommercial use, distribution, and reproduction in any medium, provided the original author(s) and source are credited.

\section{References}

1. Balsan S, Garabedian M, Larchet M, Gorski AM, Cournot G, Tau C, Bourdeau A, Silve C, Ricour C (1986) Long-term nocturnal calcium infusions can cure rickets and promote normal mineralization in hereditary resistance to 1,25-dihydroxyvitamin D. J Clin Invest 77:1661-1667

2. Basu RA, Elmer K, Babu A, Kelly CA (2000) Coeliac disease can still present with osteomalacia! Rheumatology Oxford 39:335-336

3. Clements MR, Davies M, Fraser DR, Lumb GA, Mawer EB, Adams PH (1987) Metabolic inactivation of vitamin D is enhanced in primary hyperparathyroidism. Clin Sci Lond 73:659-664 
4. Corazza GR, Di SA, Cecchetti L, Tarozzi C, Corrao G, Bernardi M, Gasbarrini G (1995) Bone mass and metabolism in patients with celiac disease. Gastroenterology 109:122-128

5. De Boer WA, Tytgat GN (1992) A patient with osteomalacia as single presenting symptom of gluten-sensitive enteropathy. J Intern Med 232:81-85

6. Farthing MJ, Rees LH, Dawson AM (1983) Male gonadal function in coeliac disease: III. Pituitary regulation. Clin Endocrinol Oxf 19:661-671

7. Fiore CE, Pennisi P, Ferro G, Ximenes B, Privitelli L, Mangiafico RA, Santoro F, Parisi N, Lombardo T (2006) Altered osteoprotegerin/RANKL ratio and low bone mineral density in celiac patients on long-term treatment with gluten-free diet. Horm Metab Res 38:417-422

8. Garcia-Porrua C, Gonzalez-Gay MA, Vila-Alvarenga S, Rivas MJ, Soilan J, Penedo M (2000) Coeliac disease and osteomalacia: an association still present in Western countries. Rheumatology(Oxford) 39:1435

9. Hepner GW, Jowsey J, Arnaud C, Gordon S, Black J, Roginsky M, Moo HF, Young JF (1978) Osteomalacia and celiac disease: response to 25-hydroxyvitamin D. Am J Med 65:1015-1020

10. Kozanoglu E, Basaran S, Goncu MK (2005) Proximal myopathy as an unusual presenting feature of celiac disease. Clin Rheumatol 24:76-78

11. Lips $P$ (2007) Relative value of $25(\mathrm{OH}) \mathrm{D}$ and $1,25(\mathrm{OH}) 2 \mathrm{D}$ measurements. J Bone Miner Res 22:1668-1671

12. McFarlane XA, Bhalla AK, Reeves DE, Morgan LM, Robertson DA (1995) Osteoporosis in treated adult coeliac disease. Gut 36:710-714

13. Miller KK, Lee EE, Lawson EA, Misra M, Minihan J, Grinspoon SK, Gleysteen S, Mickley D, Herzog D, Klibanski A (2006) Determinants of skeletal loss and recovery in anorexia nervosa. J Clin Endocrinol Metab 91:2931-2937

14. Molteni N, Bardella MT, Vezzoli G, Pozzoli E, Bianchi P (1995) Intestinal calcium absorption as shown by stable strontium test in celiac disease before and after gluten-free diet. Am J Gastroenterol 90:2025-2028
15. Mustalahti K, Collin P, Sievanen H, Salmi J, Maki M (1999) Osteopenia in patients with clinically silent coeliac disease warrants screening. Lancet 354:744-745

16. Pistorius LR, Sweidan WH, Purdie DW, Steel SA, Howey S, Bennett JR, Sutton DR (1995) Coeliac disease and bone mineral density in adult female patients. Gut 37:639-642

17. Riches PL, McRorie E, Fraser WD, Determann C, Van't HR, Ralston SH (2009) Osteoporosis associated with neutralizing autoantibodies against osteoprotegerin. N Engl J Med 361: $1459-1465$

18. Sher KS, Jayanthi V, Probert CS, Stewart CR, Mayberry JF (1994) Infertility, obstetric and gynaecological problems in coeliac sprue. Dig Dis 12:186-190

19. Staun M, Jarnum S (1988) Measurement of the 10,000molecular weight calcium-binding protein in small-intestinal biopsy specimens from patients with malabsorption syndromes. Scand J Gastroenterol 23:827-832

20. Taranta A, Fortunati D, Longo M, Rucci N, Iacomino E, Aliberti F, Facciuto E, Migliaccio S, Bardella MT, Dubini A, Borghi MO, Saraifoger S, Teti A, Bianchi ML (2004) Imbalance of osteoclastogenesis-regulating factors in patients with celiac disease. J Bone Miner Res 19:1112-1121

21. Valdimarsson T, Lofman O, Toss G, Strom M (1996) Reversal of osteopenia with diet in adult coeliac disease. Gut 38:322-327

22. Valdimarsson T, Toss G, Lofman O, Strom M (2000) Three years' follow-up of bone density in adult coeliac disease: significance of secondary hyperparathyroidism. Scand J Gastroenterol 35:274280

23. Van DM I, Karamali NS, Boeke AJ, Lips P, Middelkoop BJ, Verhoeven I, Wuister JD (2006) High prevalence of vitamin D deficiency in pregnant non-Western women in The Hague, Netherlands. Am J Clin Nutr 84:350-353

24. Walters JR (1994) Bone mineral density in coeliac disease. Gut 35:150-151

25. Weinstein RS, Underwood JL, Hutson MS, DeLuca HF (1984) Bone histomorphometry in vitamin D-deficient rats infused with calcium and phosphorus. Am J Physiol 246:E499-E505 